Jarosław Suchożebrski

\title{
THE SIZE OF THE BASIC UNIT IN GEOGRAPHICAL ANALYSIS
}

\begin{abstract}
In geographical analysis such as mathematical classification and modeling, the study area is divided into a network of basic (quasi-homogenous) units. A technique often used in the delimitation of the basic unit to be analyzed is the division of the study area into a network of uniform geometrical figures (block-centered grid). This article presents two objective methods for dividing the surface area of the study region into a network of basic units. The geometric method makes it possible to determine the optimal size of the basic unit, relative to the surface area being analyzed. This method may be used in analysis conducted on a regional scale, in which case the analysis and the results are characterized by a greater degree of generalization. Geostatistical methods (semivariance analysis and nearest-neighbor analysis) make it possible to determine the size of the cell in the grid of quasi-homogenous units, based on the spatial variation of elements in the natural environment and on the placement of data points. These methods can be recommended for the analysis of small areas (e.g. small drainage areas), when highly detailed data and results are required.
\end{abstract}

Key words: quasi-homogenous units, semivariance, nearest-neighbor method.

Physico-geographical analysis is most often conducted within naturally occurring - morphological, hydrological, climatic etc. - environmental units, that constitute a certain homogenous entities, and are demarcated from the geographic environment on the basis of arbitrarily set criteria (Richling, 1992). In spatial-economical analysis, the units used are artificial, e.g. based upon administrative division (communes, districts, voivodships, voting districts etc.). Another, often-used way of delimiting the basic study unit (spatial discretization) is the division of the study area into uniform geometrical units (block-centered grid). This approach is especially important in the mathematical modeling of natural environmental systems. Employing the block model significantly simplifies the image being analyzed and facilitates the identification of parameters. It also makes it possible to assign point values to larger areas. If these areas are homogenous, or nearly homogenous (quasihomogenous), with regard to physical characteristics, then the assumption that, within the boundaries of the unit, the physical characteristics are constant, is well-founded and constitutes a good approximation of the spatial layout parameters of the drainage area studied (Soczyńska, 1997).

An unresolved question regards the optimal size of the basic unit (cell resolution), especially in physico-geographical analysis and in mathematical 
modeling. Customarily, the size is set arbitrarily, depending upon the requirements of the analysis, the quality of cartographic materials and computational capacities. Numerous authors note that the size of the basic unit has an effect upon the final computation results (Gottschalk and Motovilov, 2004; Muller et al., 2000; Suchożebrski, 2001; Weisman et al., 1997).

The choice of unit block size should be based upon the degree of detail of the initial reference maps and upon the aim of the analysis. Gupta and Solomon recommend using a grid cell with dimensions $10 \mathrm{~km} \times 10 \mathrm{~km}$ for a scale of 1:250,000 and $1 \mathrm{~km} \times 1 \mathrm{~km}$ for a scale of 1:50,000 (Pociask-Karteczka, 1995). Enderlein, Glugl and Eyrich (after Simmers, 1984) base the size of the unit on the surface area of the region being studied, by using the following geometric formula:

$$
0.05 \sqrt{A} \leq l \leq 0.1 \sqrt{A}
$$

where

$A=$ the surface area of the region studied (in $\mathrm{km}^{2}$ ),

$l=$ the width of the grid cell (in $\mathrm{km}$ ).

To specify the optimal size of the unitary basic block, one can use various geostatistical methods. One geostatistical method is semivariance, which is based on a semivariogram. It was developed by Matheron (1963) to be used for the quantitative description of the spatial differentiation of variables phenomenon. This method is described in detail by numerous authors, including Goovaerts (1998), Li et al. (1994), Magnuszewski (1999), Mejierink et al. (1994) and Rossi et al. (1992), as well as in Spatial Analysis in Ecology (1999).

Semivariance () illustrates the degree of spatial dependence between data points, as a function of distance $(h)$. This dependence is most often represented by the formula:

where

$$
\gamma(h)=\frac{1}{2 N(h)} \sum_{i=1}^{N(h)}\left[z\left(x_{i}\right)-z\left(x_{i}+h\right)\right]^{2}
$$

$N(h)=$ the number of pairs of data points within the area being considered,

$h$ units apart,

$z\left(x_{i}\right)=$ the value of variable $z$ at point $x_{i}$, $z\left(x_{i}+h\right)=$ the value of variable $z$ at point $x_{i}+h$.

It is also possible to compute the semivariance based on digital maps presented as raster images. In this case, the semivariance is computed, with the formula: 


$$
\gamma(h)=\frac{\sum x^{2}+\sum y^{2}-\sum x y}{2 m}
$$

where

$x=$ the pixel value in the original image,

$y=$ the pixel value in the image moved over by the distance of $h$ units,

$m=$ the number of pairs of pixels.

By using this formula, one obtains the semivariance value, computed separately in the $(x)$ direction (horizontal variance) and in the $(y)$ direction (vertical variance) (Carr, 1999; Magnuszewski, 1999).

Using the semivariance method, one assumes that the correlation between the data points decreases as the distance increases and ceases to exist when the distance reaches a certain limit. The graph showing the semivariance as a function of this distance is the semivariogram, which is characterized by having 3 points: the threshold, the range and the nugget variance. The nugget variance is the lowest value of the semivariance, given the distance of 0 . In practice, the semivariance often does not reach the value of 0 , due to "interference" which can be caused by measurement errors, the sampling method used, variations in the data occurring over time etc., among other factors. Semivariance increases with distance and usually, after reaching a certain limit, called the range, it oscillates around a constant value - the threshold. The range specifies the distance beyond which the spatial correlation between the points disappears. This is used in practice in statistical interpolation methods ("kriging").

In studies, models are often used to help describe the experimental (computed) semivariograms. In the literature, one may encounter many equations for the model of a semivariogram. Those most often used in practice are:

- The linear model with a range described by the following formulas:

$$
\begin{array}{ll}
\gamma(h)=C_{0} & \text { when } h=0 \\
\gamma(h)=C_{0}+\left(h \frac{C}{a}\right) & \text { when } 0<h \leq a \\
\gamma(h)=C_{0}+C & \text { when } h>a
\end{array}
$$

- The exponential model

where

$$
\gamma(h)=C_{0}+C\left[1-\exp \left(\frac{-|h|}{b}\right)\right]
$$

$C_{0}=$ the nugget variance, 
$C_{0}+C=$ the sill,

$a=$ the range,

$h=$ the distance,

$b=$ the distance at which the semivariance reaches $95 \%$ of the threshold $(b=a / 3)$ (Fig. 1).

The spherical, Gaussian and other models, as well as their variations, are used to describe semivariance, in addition to the above models. It is also possible to apply compound models of semivariograms with various nugget values (Goovaerts, 1998). Most often, the model is made to fit the computed (original) semivariance, by applying regression analysis; the coefficient of determination $\left(r^{2}\right)$ is used to indicate the degree of fit (van den Pol-van Dasselaar et al., 1998).

The semivariance method can be used to determine the optimal density of the data grid (McBratney et al., 1986). Magnuszewski (1999) reports that, while designing the observation grid, one should make the distance between the points be $3-5$ times shorter than the length of the range. Mejierink et al. (1994) consider $2 / 3$ of the range to be the optimal distance, since using a fraction any larger causes the spatial associations between the numerical characteristics to disappear. A similar assumption can be made when designing a grid of basic units. Setting up a unitary quasi-homogenous basic block with sides that are $1 / 3-1 / 5$ of the range makes it possible to maintain the high homogeneity and correlation of the data within the cell of the grid, while at the same time revealing the changeability of the phenomenon throughout the entire area being studied.

In many cases, the semivariogram method cannot be used to specify the optimal size of basic units. This includes e.g. variables representing physical

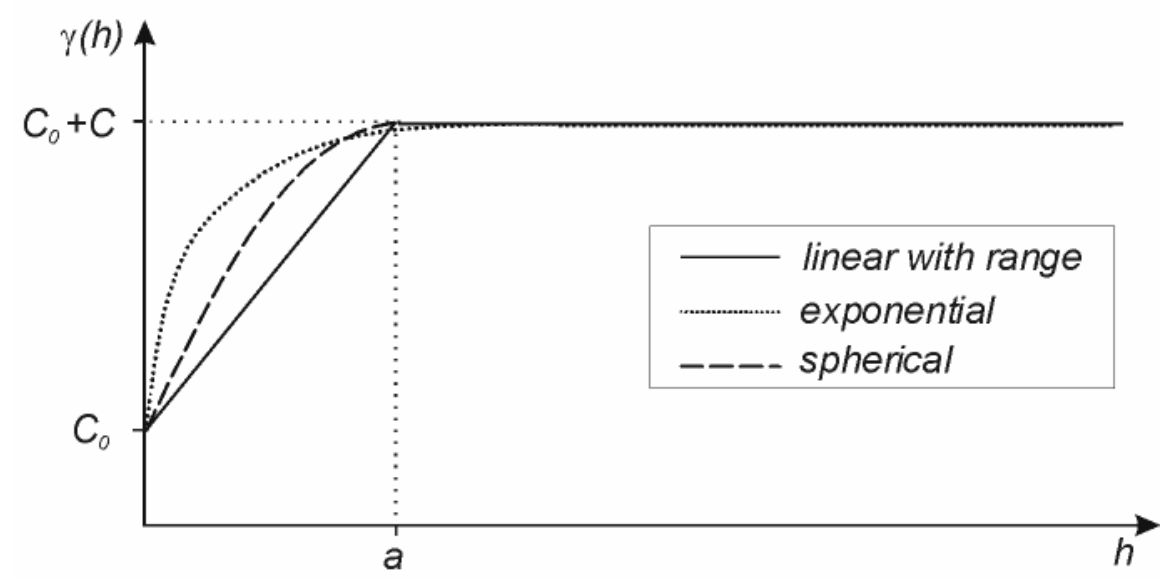

Fig. 1. Models of semivariogram; $\gamma(h)$ - semivariance, $h$ - distance, $C_{o}$ - nugget variance, $C+C_{o}-$ sill, $a-$ range. 
soil characteristics, identified as maps of points. Studies conducted by various authors indicate that the spatial dependences of certain physical soil characteristics (incl. water conductivity and water reserves within the soil) disappear, given very short - in the range of several to a dozen meters distance intervals $(h)$ (Logsdon, Jaynes, 1996; Zavattaro et al., 1999). The size of the grid cell has to correspond to the density of the data points in the studied region. Too small a number of data points often makes it impossible to divide the region into small quasi-homogenous units by using the semivariance analysis method. For this reason, to optimize this number of points, one can employ the nearest-neighbor analysis method.

The nearest-neighbor analysis method makes it possible to characterize the location of points in two-dimensional space, in relation to other points. It was introduced at the end of the $19^{\text {th }}$ century and found an application in ecology (Spatial..., 1999) among other fields. The method is based on calculating the average distance between points closest to each other, and also a theoretical distance, with the assumption that the points are distributed in space in a random fashion. Next, it involves comparing these distances, and calculating the probability of one, two or more points occurring within a certain distance of each other (Ilwis..., 1997). The theoretical distance between two randomly positioned points is calculated with the formula:

$$
d_{i}=\frac{0.5}{\sqrt{n / A}}
$$

where

$n=$ the number of data points,

$A=$ the surface area of the region studied.

Application Examples: The methods presented were used for the optimization of the basic block grid cell size during analysis conducted at the drainage area of the upper Wilga River (the right tributary of the Vistula). The surface area of the region being studied covers $231.6 \mathrm{~km}^{2}$. Digital maps illustrating the diagnostic variables (components of the natural environment) were generated: a map of the average groundwater table depth during the years 1974-1991, a map showing the depth of the rhizosphere, and a map of the terrain slope; all based on data from the Meteorology and Water Management Institute and from the author's own field studies. The digital maps were presented as raster images, with one raster corresponding to an area of $25 \mathrm{~m} \times 25 \mathrm{~m}$. Three digital maps of points were also generated, representing the values of the coefficients of hydraulic conductivity, water reserves (in the soil) corresponding to the field water storage capacity and permanent wilting point.

The size of the basic block was computed by the geometric method (formula no. 1). The limits (l) obtained for the cell of the grid were:

$$
0.8 \leq l \leq 1.5
$$




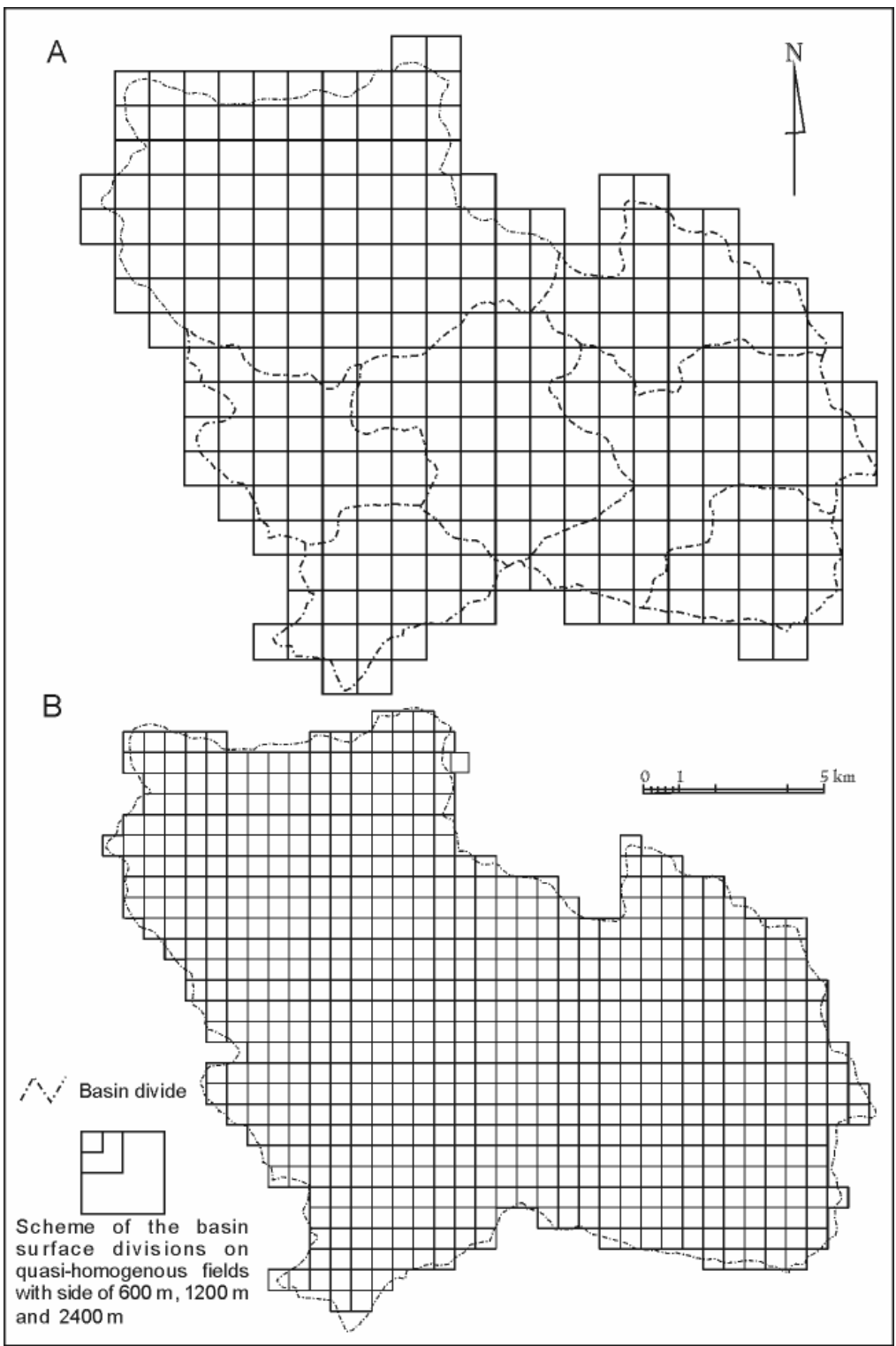

Fig. 2. Division of the surface of the upper Wilga River basin into quasi-homogenous units, by the geometrical method (A) and the geostatistical methods (B).

According to this relation (9), one can assume that the optimal length of the side of the square-shaped basic block obtained with the geometric method equals to $1 \mathrm{~km}$. By adopting these dimensions, it is possible to divide the drainage area's surface into 276 quasi-homogenous blocks, by superimposing a $1 \mathrm{~km}$ grid from a topographic map with the scale of 1:25,000 (Fig. 2). 
Table 1.

The spatial parameters of semivariogram models computed on the basis of raster maps: $C_{0}=$ the nugget variance, $C+C_{0}=$ the sill, $a=$ the range [in meters], $r^{2}=$ the fit of the theoretical equation (model) to the original semivariogram (the coefficient of determination); $l=$ the length of the side of the quasi-homogenous block (1/5a to $1 / 3 a)$ [in meters]

\begin{tabular}{|c|c|c|c|c|c|c|c|}
\hline Digital map & $\begin{array}{c}\text { Direction of } \\
\text { Computation }\end{array}$ & $\begin{array}{c}\text { Semivariogram } \\
\text { Model }\end{array}$ & $C_{0}$ & $C+C_{0}$ & $a$ & $r^{2}$ & $l$ \\
\hline Terrain Slope & $\mathrm{x}$ & exponential & 0.22 & 1.0 & 2275 & 0.90 & $455-758$ \\
\hline & $\mathrm{y}$ & $\begin{array}{c}\text { exponential } \\
\text { and linear }\end{array}$ & 0.26 & 1.0 & 2825 & 0.91 & $565-942$ \\
\hline $\begin{array}{c}\text { Groundwater } \\
\text { table Depth }\end{array}$ & $\mathrm{x}$ & $\begin{array}{c}\text { exponential } \\
\text { and linear }\end{array}$ & 0.09 & 1.17 & 5550 & 1.00 & $1110-1850$ \\
\hline & $\mathrm{y}$ & exponential & 0.10 & 1.16 & 3900 & 0.98 & $780-1300$ \\
\hline $\begin{array}{c}\text { Rhizosphere } \\
\text { Depth }\end{array}$ & $\mathrm{x}$ & exponential & 0.81 & 5.71 & 1925 & 0.98 & $385-642$ \\
\hline & $\mathrm{y}$ & exponential & 1.06 & 5.89 & 1825 & 0.97 & $365-608$ \\
\hline
\end{tabular}

In the second variant, the division of the drainage area's surface into a grid of square basic blocks was done by using geostatistical methods. The digital maps - the average groundwater table depth (hydroisobath) map, the rhizosphere depth map, and the terrain slope map - were the basis for the creation of the semivariogram models. The calculations were performed with Ilwis 2.1, a geoinformatic computer program. The parameters of the semivariogram model were optimized to maximize the values of the coefficients of determination $\left(r^{2}\right)$ between the original and the theoretical semivariogram values (models) (Table 1$)$.

When the variables were presented as digital maps of points, nearestneighbor analysis was used to determine the size of the unitary cell in the grid of basic blocks. It was determined that the length of the side of the square-shaped, quasi-homogenous block should not be less than $1800 \mathrm{~m}$ for the analysis of the coefficients of hydraulic conductivity in the aeration zone and water reserves in the soil at half of the field water storage capacity; and should not be less than $1600 \mathrm{~m}$ for permanent wilting point (Table 2).

Semivariance analysis and nearest-neighbor analysis carried out on the basis of digital maps indicate that due to variations in the drainage area's natural environment, the same size of basic block cannot be used for all the diagnostic variables. It is possible however to use differently sized grid cells, depending upon the spatial variation of the diagnostic variables included, or the density of the data points. The reference point for identifying diagnostic variables inside quasi-homogenous units should be the smallest basic unit, the size of which is determined by the analysis of the semivariograms. 
The distance [in meters], at which the probability that the given number of data points will be present, is 1 .

\begin{tabular}{|l|c|c|c|c|c|}
\hline \multicolumn{1}{|c|}{ Digital Map } & All points & 1 point & 2 points & 3 points & 4 points \\
\hline $\begin{array}{l}\text { Coefficient of hydraulic } \\
\text { conductivity }\end{array}$ & 24000 & 1800 & 1800 & 2000 & 2200 \\
$\begin{array}{l}\text { Field (water storage) } \\
\text { capacity }\end{array}$ & 24000 & 1500 & 1600 & 1800 & 2200 \\
$\begin{array}{l}\text { Permanent wilting } \\
\text { point }\end{array}$ & 24000 & 1800 & 1800 & 2000 & 2400 \\
\hline
\end{tabular}

Consequently, the square unit with sides $0.6 \mathrm{~km}$ long was chosen as the basis, corresponding to the spatial variation of the drainage area slope and to the depth of the rhizosphere. This length fits within the interval of $1 / 5-1 / 3$ of the range. Groundwater depths were determined within a square unit with sides $1.2 \mathrm{~km}$ long, which was composed of 4 units with sides $0.6 \mathrm{~km}$ long.

The filtration coefficients and the retention characteristics of soil profiles were identified within blocks with sides $0.6 \mathrm{~km}$ long. When the data point did not fit inside the grid cell thus defined, the variables were identified first within a unit with sides $1.2 \mathrm{~km}$ long, and then $2.4 \mathrm{~km}$ long (16 blocks with sides $0.6 \mathrm{~km}$ long). Variable values in the basic units were determined by various overlaying digital maps (thematic layers). An average of the variables (points) occurring within each unit block was computed. The use of the different sizes of grid cells ensured that at least one point (soil profile) was present within each cell.

The result of applying the above method of diagnostic variable identification was the division of the drainage area's surface into 647 square-shaped quasi-homogenous units with sides $0.6 \mathrm{~km}$ long (Fig. 2).

\section{SUMMARY AND CONCLUSIONS}

The methods for determining the optimal size of the basic unit (cell resolution) vary with regard to computational techniques and the amount of work required, as well as the possible applications (classification, mathematical modeling etc.). The conclusions which follow are:

1. The use of geostatistical methods to define the cell resolution makes it possible to take into account variations occurring in the natural environment. From among these methods, semivariogram analysis yields good results when the diagnostic variables identified on the basis of digital maps are presented as raster images. In the case of diagnostic variables identified on the basis of soil profile characteristics, the size of the unitary cell should be adjusted to the density of points at which the samples were taken. Here one could use the nearest-neighbor method of analysis. 
2. Defined by geostatistical methods, the varying cell sizes in the grid of quasi-homogenous units make it possible to adjust the size to fit the varying conditions present in the natural environment and to fit the density of the soil profiles. In the identification of the variables, one needs to take into account that there is a tradeoff between precision, and necessary generalization, as well as computational capabilities.

3. Defining quasi-homogenous units with the help of geostatistical methods can be done for the analysis of small areas, when more detailed data and results are required.

4. The geometric method for determining the size of the cell in the grid of the basic units can be used on large study areas (e.g. drainage basins, drainage areas), when the analysis and results are more general.

\section{REFERENCES}

C a r r J.R., 1999, Classification of digital image texture using variograms, [in:] Atkinson P.M., Tate N. (ed.), Advances in remote sensing and GIS analysis. Chichester-New York, John Wiley and Sons Ltd.

Goovaerts P., 1998, Geostatistical tools for characterising the spatial variability of microbiological and physico-chemical soil properties. Biol. Fertil. Soils, 27.

Gottschalk L., Motovilov Y., 2004, Process Of Spatial Parameterisation and Scale Application Of Distributed Model to the Glomma River Basin, Norway. Geophysical Research Abstracts, 6.

Ilwis 2.1: Reference Guide, 1997, Intern. Inst. for Aerosp. Survey and Earth Sci., Enschede.

Li D., Li L., Larry W., 1994, A moving window semivariance estimator. Water Resour. Res., 30, 5 .

Logston S.D., Jaynes D.B., 1996, Spatial variability of hydraulic properties in a multilayered soil profile. Soil Sci. Soc. Am. J., 60.

Magnuszewski A., 1999, GIS w geografii fizycznej [GIS in Physical Geography; in Polish]. Wyd. Nauk. PWN, Warsaw.

Matheron G., 1963, Principles of geostatistics. Econ. Geol., 58.

McBratney A.B., Webster W., 1986, Choosing function for semi-variograms of soil properties and fitting them to sampling estimates. J. Soil Sci., 37, 4.

Mejierink A.M.J., de Brouwer H.A.M., Mannaerts C.M., Valenzuela C.R., 1994, Introduction to the use of Geographic Information Systems for practical hydrology. ITC Publ. No. 23, Enschede.

Muller F., Cochonneau G., Guyot J.-L., Seyler F., 2000, Watershed extraction using together DEM and drainage network: Application to the whole Amazonian basin. Proceedings of the 4th International Conference on Integrating GIS and Environmental Modeling (GIS/EM4): Problems, Prospects and Research Needs. Banff, Canada, September $2-8,2000$.

Pociask-Karteczka J., 1995, Założenia metodyczne regionalizacji hydrologicznej na przykładzie dorzecza górnej Wisły [Methodical Foundations of Hydrological Regionalization, the Example of the Upper Vistula Drainage Basin; in Polish]. Rozpr. Habil. UJ [PostDoctoral Habilitation Dissertation, Jagiellonian University], 291.

Richling A., 1992, Kompleksowa geografia fizyczna [Complex Physical Geography; in Polish]. Warsaw, Wyd. Nauk. PWN.

Rossi J.P., Lavelle P., Albrecht A., 1992, Geostatistical tools for modelling and interpreting ecological spatial dependence. Ecol. Monogr., 62, 2.

Sim mers I., 1984, A systematic problem-oriented approach to hydrological data regionalization. J. Hydrol., 73. 
Soczyńsk a U., 1997, Hydrologia dynamiczna [Dynamic Hydrology; in Polish]. Warsaw, Wyd. Nauk. PWN.

Suchożebrski J., 2001, Warunki migracji zanieczyszczeń do wód podziemnych w nizinnej zlewni rolniczej (na przykładzie zlewni górnej Wilgi) [Conditions for the Migration of Contaminants into the Groundwater in Lowland, Agricultural Drainage Areas (The Example of the Upper Wilga Drainage Area); in Polish], [in:] Jaworski J., Szkutnicki J., Dynamika obiegu wody w zlewniach rzecznych [Water Circulation Dynamics in River Drainage Areas; in Polish]. IMGW, [The Polish Institute of Meteorology and Water Management] Warsaw.

Spatial analysis in ecology, 1999. Duke University, Landsape Ecol. Lab., Durham. (URL: http:/ /www.env.duke.edu/lel/env352.html).

Van den Pol-van Dasselaar A., Corré W.J., Priemé K., Klemedtsson Ĺ.K., Weslien P., Stein A., Klemedtss on L., Oenema O., 1998, Spatial variability of methane, nitrous oxide, and carbon dioxide emission from drained grasslands. Soil Sci. Soc. Am. J., 62.

Weis man M.L., Skamarock W.C., Kle m p J.B., 1997, The resolution dependence of explicitly modelled convective systems. Mon. Wea. Rev., 125.

Zavattaro L., Jarvis N., Perss on L., 1999, Use of similar media scaling to characterise spatial dependence of near saturated hydraulic conductivity. Soil Sci. Soc. Am. J., 63.

English translation: Joanna M. Kwiatowska 